\title{
A new species and a new record of the genus Scymbalopsis (Coleoptera: Staphylinidae: Paederinae: Paederini)
}

\author{
Alexey V. SHAVRIN*) \& Alexander ANICHTCHENKO \\ Institute of Life Sciences and Technologies, Daugavpils University, Vienibas 13, Daugavpils LV-5401 Latvia \\ ") corresponding author: e-mail: ashavrin@hotmail.com
}

\author{
Accepted: \\ $21^{\text {st }}$ May 2019 \\ Published online: \\ $27^{\text {th }}$ May 2019
}

\begin{abstract}
A new species, Scymbalopsis persica sp. nov. (Staphylinidae: Paederinae: Paederini), is described and illustrated based on three specimens collected in Lorestan province, Iran. The new species can be distinguished from the remaining species of the genus by the paler coloration, moderately wide forebody with dense and long setation, and other details of the morphology of the body and aedeagus. Detailed bionomic data for $S$. persica sp. nov. are presented. An additional record from Kyrgyzstan and photograph of the habitus of S. kirghizica Gusarov, 1994, and a key to the species of Scymbalopsis Reitter, 1909 are provided. The genus is recorded for the first time from Iran.
\end{abstract}

Key words. Coleoptera, Staphylinidae, Paederinae, Scymbalopsis, taxonomy, new species, new record, Iran, Kyrgyzstan, Palaearctic Region

Zoobank: http://zoobank.org/urn:lsid:zoobank.org:pub:EEFEBBF9-EA45-456C-AC4A-A9C766EBE998

(C) 2019 The Authors. This work is licensed under the Creative Commons Attribution-NonCommercial-NoDerivs 3.0 Licence.

\section{Introduction}

The paederine genus Scymbalopsis was erected by REITTER (1909) for Scimbalium grandiceps described by the same author (REITTER 1892) from 'Margelan' (today: Margilon, Fergana Province, Uzbekistan). In the same year, the name Scimbalium grandiceps Reitter, 1892 (primary junior homonym of the name $S$. grandiceps Jacquelin du Val, 1853) was replaced by $S$. reitteri by JAKOBSON (1909). GuSAROv (1994) redescribed S. reitteri Jakobson, 1909 and described two species from Central Asia: S. beloussovi from Tajikistan and S. kirghizica from Kyrgyzstan. Scymbalopsis belongs to the subtribe Lathrobiina Laporte, 1835, containing twelve genera in the Palaearctic Region (Schülke \& SMEtana 2015). Based on the large body size, pale coloration and dilated protarsomeres I-IV in both sexes, species of the genus are similar to those of the genus Scymbalium Erichson, 1835, but they can be distinguished by the presence of very long setation of the slightly flattened forebody, markedly wider head with rounded temples, longer legs, significantly shorter posterolateral processes of the abdominal segment IX, general shape of the aedeagus, etc. Species of this obscure genus are extremely rare in collections and, at present, known only from a few specimens of the type series.
The second author collected a series of a new species of Scymbalopsis during his trip to north-western Iran (Lorestan Province) in April-May 2007. A description of this spectacular fourth species of the genus is provided in the present study. In addition, a new record of S. kirghizica Gusarov, 1994 from Kyrgyzstan and a key to Scymbalopsis species are given.

\section{Material and methods}

Specimens were studied using Nikon SMZ 745T and a Nikon Eclipse E200 stereomicroscopes. All measurements are given in millimeters and were made with an ocular micrometer mounted on a stereoscopic microscope. A digital camera (Sony Alpha DSLR-A300) was used for photographs of habitus and aedeagus. All figures were modified using Adobe Photoshop software. Data on labels are given verbatim in single quotations; different lines are separated by a single vertical bar, additional notes are given in square brackets. All types are provided with an additional label: 'HOLOTYPE [or PARATYPE] |Scymbalopsis | persica sp.n. | Shavrin A.V. \& Anichtchenko A. des. 2019' [red rectangular printed label]. In the specimen listings, 'specimen(-s) dissected' means that plastic plates with aedeagus in Canada balsam were pinned under the 
card with the beetle (male); abdominal tergites VIII-X, sternite VIII and female genital segment are glued on an additional card).

The specimens examined are deposited in the following collections:

ASCD A.V. Shavrin collection, Daugavpils, Latvia;

ZIN Zoological Institute of the Russian Academy of Sciences, St. Petersburg, Russia (B. A. Korotyaev).

\section{Results}

\section{Scymbalopsis persica sp. nov.}

$$
\text { (Figs 1, 3-12) }
$$

Type material. НоLотYPE: $\hat{\jmath}$ (specimen dissected; antennomeres 6-11 of right antenna are missing), 'SW IRAN: Lorestan Province, $55 \mathrm{~km} \mathrm{~N}$ Andimeshk, | Shartakht vill. [3249'12.0”'N 4802'24.0”'E; $\mathrm{h}=173 \mathrm{~m}$ a.s.1.] 4.05.2007| A. Anichtchenko leg.' (ZIN). PARATYPES: 1 1 (specimens dissected): same data as the holotype (ASCD).

Description. Measurements $(\mathrm{n}=3$, in $\mathrm{mm})$ : maximum width of head including eyes: 2.2-2.5; length of head (from base of labrum to neck constriction): 2.13-2.3; length of eye (longitudinal): 0.4 ; length of temples (from posterior margin of eye to neck constriction): 1.2-1.3; length of antenna: 6.0 ; length of pronotum: 2.2-2.5; maximum width of pronotum: 2.0-2.5; sutural length of elytra (length of elytra from apex of scutellum to posterior margin of sutural angle): 1.6-1.7; maximum width of elytra: 2.2 ; length of metatarsus (without tarsal claws): 2.2; length of aedeagus: 1.1; body length: 12.2-14.1. Habitus as in Fig. 1.

Body yellowish-brown; head, antennomeres, pronotum, protibiae and tarsi brown to reddish-brown; inner margins of mandibles, base of antennae and tentorial spots reddish-brown; maxillary palpi, apical parts of antennomeres, femora and tibiae yellow.

Head large, about as long as wide; temples convex, about three times as long as eyes. Mandibles with markedly broad basal part; cutting edge of each mandible with row of variable teeth, with largest preapical tooth divided into two pointed apical parts. Clypeus and frons with irregular and distinctly sparse, moderately small and deep punctation; middle and basal portions densely punctate, punctures moderately large and deep, interspaces between these punctures two to three times as wide as diameter of nearest puncture; temples somewhat denser punctate than that in middle. Dorsal surface without microsculpture, temples (in lateral view) with indistinct transverse microsculpture. Pubescence composed of short non-erect and very long erect setae in anterior and lateral portions. Antennae long, reaching apical third of elytra when spread backwards; antennomeres markedly oblong, each antennomere with yellow moderately dense pubescence; length $\times$ width of antennomeres (holotype): I: $0.50 \times 0.25$, II: $0.42 \times 0.22$, III: $0.71 \times 0.22, \mathrm{IV}-\mathrm{V}: 0.61 \times 0.22$, VI-X: $0.52 \times 0.22$, XI: $0.56 \times 0.22$.

Pronotum slightly longer than wide, widest in apical third, markedly narrowed posteriad, slightly narrower than head, bordered at base and sides (lateral border visible from above); basal margin widely sinuate. Punctation irregular, slightly smaller and sparser than that in middle of head. Surface between punctures without microsculpture.
Lateral sides with $12-15$ pairs of long dark setae (in one paratype missing).

Scutellum relatively large, with small punctation, setation and transverse microsculpture.

Elytra visibly shorter than pronotum, parallel-sided, about as long as wide; humeral projections well developed; longitudinal epipleural furrow reaching very narrowly bordered apical margin; apical angle of each elytron distinctly protruded, with apical margin markedly truncated at suture. Surface without microsculpture, with dense, large and deep punctuation. Humeri with two distinct, crenulate tubercles, each with two very long setae. Wings reduced.

Legs very long, with tibiae covered by dense pubescence (very dense in protibiae); metatarsus about as long as metatibia, with basal metatarsomere distinctly longer than apical segment.

Abdomen slightly widened towards segment VI, with distinctly widened latero-apical parts of paratergites III-V. Abdominal tergites with dense and moderately small punctation, hardly getting sparser towards apex; surface between punctures with indistinct transverse microsculpture. Pubescence very dense, non-erect, middle and lateral portions of tergites usually with long, black, erect setae.

Male. Protarsomeres 1-3 significantly widened, with basal protarsomeres about as wide as apical part of protibia. Apical margin of abdominal tergite VIII rounded (Fig. 6). Apical margin of abdominal sternite VIII slightly sinuate (Fig. 7). Abdominal tergite IX and tergite $\mathrm{X}$ as in Fig. 8. Aedeagus relatively wide in middle, gradually tapered towards somewhat acute apex; parameres narrow, slightly exceeding apex of aedeagus, with three pairs of short setae along apical part of inner margin (Figs. 3, 5); internal sac short and convolute, with numerous small thorns and sclerotized semicircular lamella in apical portion. Aedeagus laterally as in Fig. 4.

Female. Protarsomeres 1-3 distinctly narrower. Apical margins of abdominal tergite VIII (Fig. 9) and sternite VIII (Fig. 10) rounded to straight. Genital segment as in Fig. 11. Differential diagnosis. The new species can be distinguished from all known species of Scymbalopsis by the paler coloration, wider forebody with denser and longer setation, smaller punctation, shorter temples in relation to eye length, shapes of basal margin of the pronotum, and lateral margins of paratergites III-V. The aedeagus is similar to that of $S$. reitteri, but differs by the wider apical part and completely different structure of the internal sac.

Habitat. All specimens were collected from a steep slope of karst terrain with sparse Quercus persicus (Fig. 12), under large stones during the morning, when the stones were cold and covered with drops of dew. In the evening, the stones were very warm and did not have beetles underneath. Specimens of $S$. persicus sp. nov. were collected together with depigmented species of Platyderus Stephens, 1827 and the endemic Laemostenus luristanus Casale, 1988 (Carabidae).

Etymology. The specific epithet is the Latinized adjective derived from the old name of the country where the specimens were collected. 

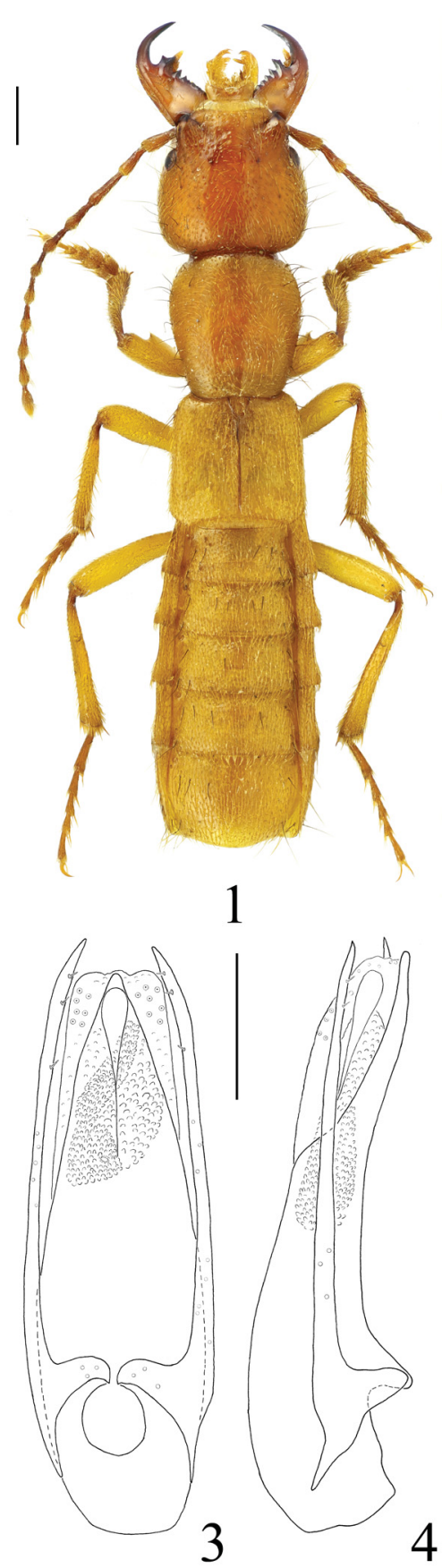
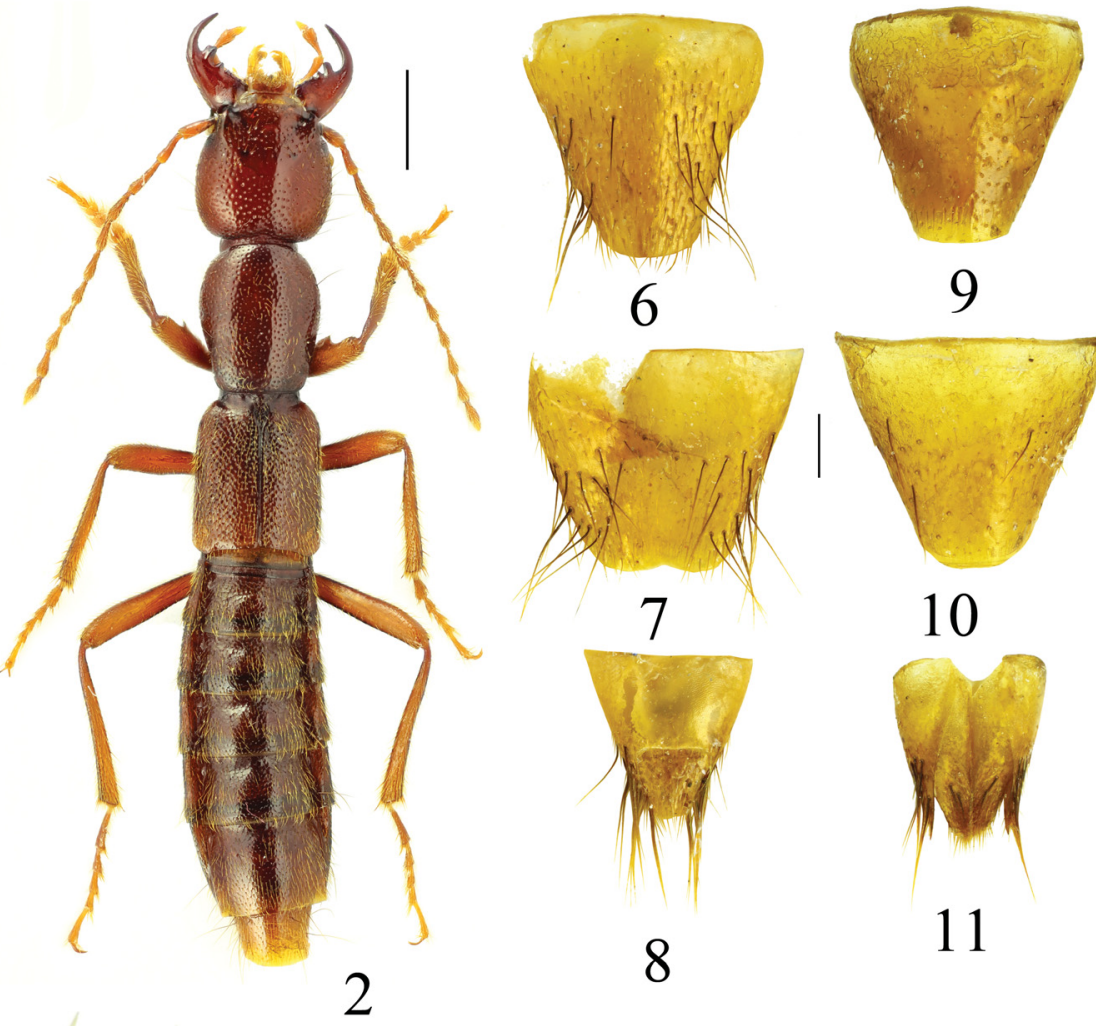

9
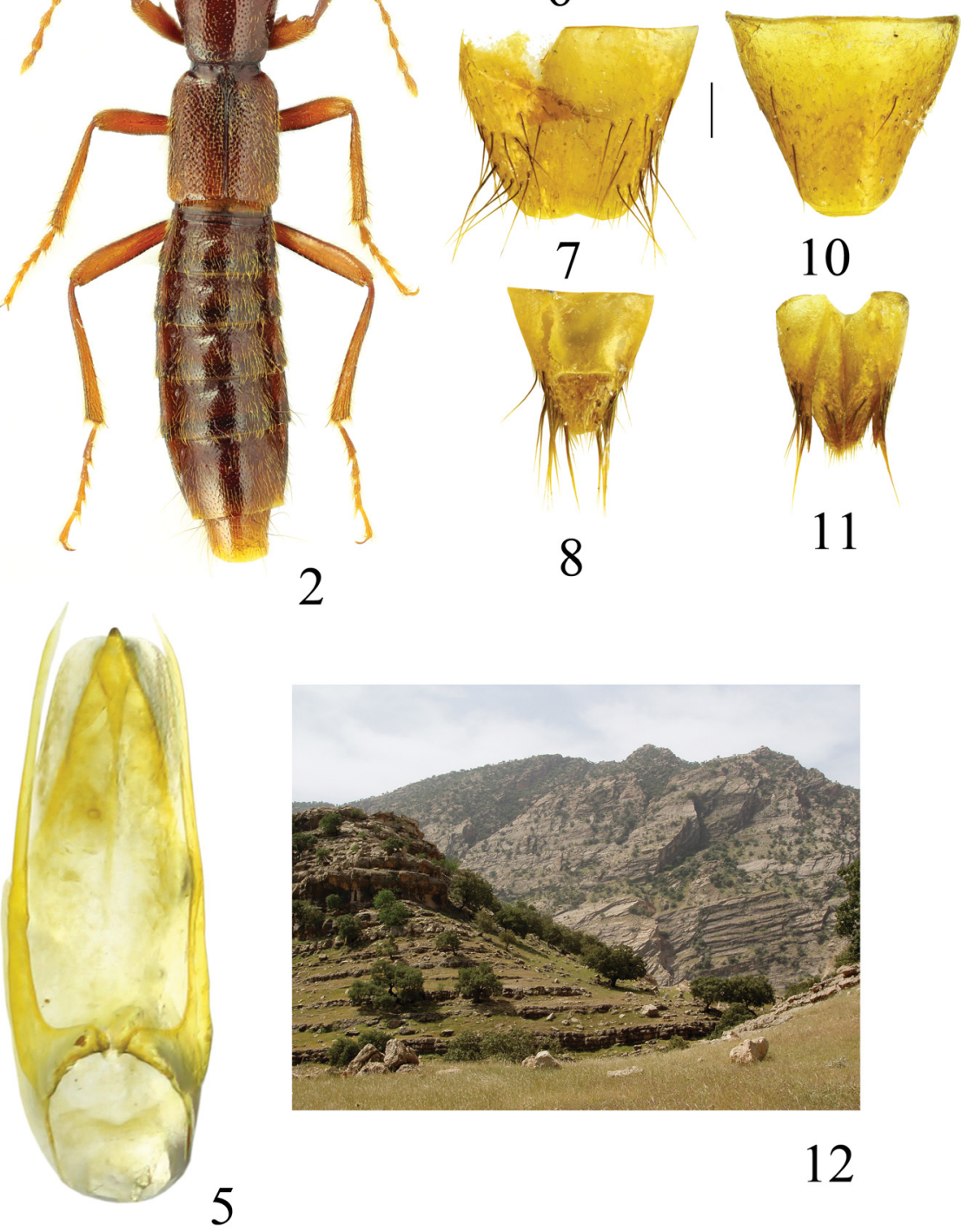

Figs 1-12. Scymbalopsis persica sp. nov. and S. kirghizica Gusarov, 1994. 1-2 - dorsal habitus (1 - S. persica sp. nov., holotype; 2 - S. kirghizica). 3-11 - morphology of S.persica sp. nov.: 3-5 - aedeagus (3-4 - paratype, parameral and lateral view; 5-holotype); 6-11 - abdominal segments, dorsal view (6-10) or ventral view (11): 6 - male tergite VIII, 7 - male sternite VIII, 8 - male tergite IX and X, 9 - female tergite VIII, 10 - female sternite VIII, 11 - female genital segment. 12 - type locality of $S$. persica sp. nov. in Lorestan, Iran. Scale bars: 1.0 mm (Figs 1-2), 0.25 mm (Figs 3-11).

\section{Scymbalopsis kirghizica Gusarov, 1994 \\ (Fig. 2)}

Scymbalopsis kirghizica Gusarov, 1994: 442

Material examined. 1 (apical abdominal segment and aedeagus are missing): 'Kirgizia [=Kyrgyzstan] Sary Chelek Lake. 30.05.1993. Ovchinnikov S.V.', 'Scymbalopsis kirghizica Gusarov V.I. Gusarov det. 1996' (ASCD).

Remarks. Scymbalopsis kirghizica was described based on two females from "Toktogul distr., Karakuldzha river" (Kyrgyzstan). The new record is located about $200 \mathrm{~km}$ west of the type locality.

\section{Key to the species of Scymbalopsis}

1 Temples very long, seven times as long as eyes. Median lobe of aedeagus very wide, sharply narrowed toward apex (see Gusarov 1994: Figs 37-38). Body length: 14.6 mm. Tajikistan. ....... S. beloussovi Gusarov, 1994

- Temples significantly shorter, three to four times as long as eyes. In species with described male, median lobe of aedeagus narrower, gradually narrowed toward apex. .. 2

2 Head distinctly longer than wide. Humeral projections poorly developed (Fig. 2). Body length: 14.6-14.8 mm. Kyrgyzstan. S. kirghizica Gusarov, 1994 
- Head about as long as wide. Humeral projections well developed.

3 Temples three times as long as eyes. Pronotum slightly longer than wide, markedly narrowed posteriad, with moderately sparse and fine punctation. Body yellowish-brown, with slightly darker head and pronotum. Apical part of median lobe of aedeagus relatively wide (Figs 3, 5). Body length: 12.2-14.1 mm. Habitus as in Fig. 1. Iran.

S. persica sp. nov.

- Temples four times as long as eyes. Pronotum distinctly longer than wide, slightly narrowed posteriad, with dense and moderately large punctation. Body reddish-brown. Apical part of median lobe of aedeagus narrow (see Gusarov 1994: Figs 31-32). Body length: 11.5 mm. Uzbekistan.

S. reitteri (Jakobson, 1909)

\section{Acknowledgements}

We are grateful to A. Smetana (Ottawa, Canada) and V. Assing (Hannover, Germany) for help with this manuscript in its early stages of preparation. We also thank
A. J. Brunke (Ottawa, Canada) for correction of the English text of the manuscript, and M. Fikáček (Praha, Czech Republic) and an anonymous reviewer for helpful comments and suggestions.

\section{References}

GUSAROV V. I. 1994: New and little-known Palaearctic Paederinae (Coleoptera: Staphylinidae). Annales de la Société Entomologique de France (Nouvelle Serie) 30: 431-446.

JAKOBSON G. G. 1909: Fasc. 7. Pp. 481-560. In: Zhuki Rossii i zapadnoy Evropy [Beetles of Russia and western Europe]. A.F. Devrien, St. Petersburg, 1024 pp. +83 pl. (in Russian).

REITTER E. 1892: Fünfter Beitrag zur Coleopterenfauna des russischen Reiches. Wiener Entomologische Zeitung 11: 59-68.

REITTER E. 1909: Fauna Germanica. Die Käfer des Deutschen Reiches. Nach der analytischen Methode bearbeitet. II Band. K. G. Lutz, Stuttgart, 392 pp, pls. 41-80.

SCHÜLKE M. \& SMETANA A. 2015: Family Staphylinidae Latreille, 1802. Pp. 304-1134. In: LÖBL I. \& LÖBL D. (eds): Catalogue of Palaearctic Coleoptera. Volume 2. Revised and updated version. Hydrophiloidea - Staphylinoidea. Brill, Leiden-Boston, 1702 pp. 